\title{
Cellular and Subcellular Organization of the 277F Agent, a Spiroplasma from the Rabbit Tick Haemaphysalis leporispalustris (Acari: Ixodidae)
}

\author{
LYLE P. BRINTON AND WILLY BURGDORFER \\ National Institute of Allergy and Infectious Diseases, Rocky Mountain Laboratory, Hamilton, Montana 59840
}

The cellular and subcellular ultrastructure of the helical 277F agent was studied in detail utilizing negative staining and ultrathin sections of fluids and/ or tissues of infected chicken embryos and Ornithodoros moubata ticks. This organism, which lacks a cell wall and axial filaments, conforms closely in size and fine structural characteristics (plasma membrane, ribosomes, fibrillar reticulum, and thin glycocalyx-like coat on the cell surface) to the genus Spiroplasma of the order Mycoplasmatales.

In 1968, Pickens et al. (10) reported the isolation and preliminary characterization of a spirochete-like organism, referred to as the $277 \mathrm{~F}$ agent, from the rabbit tick Haemaphysalis leporispalustris taken off two cottontail rabbits (Sylvilagus nuttalli) in western Montana. This organism, up to $30.0 \mu \mathrm{m}$ long and $0.1 \mu \mathrm{m}$ wide, was difficult to demonstrate by Giemsa stain, but under dark field it appeared uniformly and tightly coiled and exhibited typical corkscrewlike motility. It could regularly be maintained in embryonated chicken eggs, in which it was highly lethal, as well as in enriched liquid medium, and it passed through Berkefeld $\mathrm{N}$ but not Seitz EK filters.

One outstanding morphological feature of the $277 \mathrm{~F}$ agent was a granule-like protuberance either at one end or anywhere along the length of the cell. There was evidence (resistance to heat treatment and passage through Berkefeld filters) that these granular products were infectious and capable of producing typical spirochete-like forms (10).

The cellular ultrastructure of this helical organism has been studied utilizing transmission electron microscopy. The results reported here suggest that the $277 \mathrm{~F}$ agent is a mycoplasmalike organism closely similar to the corn stunt agent $(1,6,7)$ or to Spiroplasma citri, the "Stubborn" disease agent of citrus $(3,4,14)$.

\section{MATERIALS AND METHODS}

The $277 \mathrm{~F}$ preparations examined consisted of infected allantoic and amniotic fluids of chicken embryos of the 14th passage (seed lot no. 3) and fluids and tissues of experimentally infected Ornithodoros moubata ticks, in which the 277F agent was found to grow profusely in all the tissues (W. Burgdorfer, unpublished data). These ticks originated from a colony of $O$. moubata, which proved free of the $277 \mathrm{~F}$ agent. They were injected intracoelomically with infected chicken embryo fluids of the 16th egg passage (seed lot no. 3). Passage of the $277 \mathrm{~F}$ agent in chicken eggs was conducted as described previously (10).

For electron microscopy, allantoic and amniotic fluids of chicken eggs were harvested 5 and 6 days after inoculation. The fluids were pooled and differentially centrifuged at $480 \times g(10 \mathrm{~min})$ and $9,750 \times$ $g(30 \mathrm{~min})$ to obtain partially purified pellets. These pellets, as well as the various tissues of ticks dissected 12 to 20 days after inoculation, were fixed at 2 to $4^{\circ} \mathrm{C}$ in $3 \%$ glutaraldehyde in $0.1 \mathrm{M}$ phosphate buffer $(\mathrm{pH} 7.4$ ) for 1.0 to $1.5 \mathrm{~h}$ and washed in two changes of phosphate-buffered $0.20 \mathrm{M}$ sucrose $(\mathrm{pH}$ 7.4). Postfixation followed in phosphate-buffered (pH 7.4) $1 \%$ osmium tetroxide for $1 \mathrm{~h}$. Cells and tissues were treated with a $0.5 \%$ uranyl acetate solution followed by rapid dehydration in an ethanolic series with three changes of $100 \%$ ethanol at room temperature. Two 10-min changes of propylene oxide preceded infiltration in 1:1 and 1:2 ratios of propylene oxide and Araldite 502 overnight with subsequent embedding in Araldite 502 (8).

After polymerization (8), silver-gold to gray sections were obtained on a Porter-Blum MT-1 ultramicrotome and placed on grids covered with carbonstabilized Formvar films. Sections were stained in uranyl acetate and lead citrate (12) and examined in a Hitachi HU-11E electron microscope at $75 \mathrm{kV}$.

For negative staining, Formvar-coated grids were touched to the surface of coxal fluid exudates of infected $O$. moubata. After approximately $30 \mathrm{~s}$, excess fluid was removed by touching grids to the edge of filter paper. A drop of $1.0 \%$ phosphotungstic acid (PTA) was immediately applied and the excess was removed after 10 to $15 \mathrm{~s}$. The material was examined in the electron microscope soon after drying.

\section{RESULTS}

Negatively stained organisms in coxal fluids of $O$. moubata ticks clearly showed a spiral morphology (Fig. 1) and frequent branching (Fig. 2). Their diameters varied from approxi- 


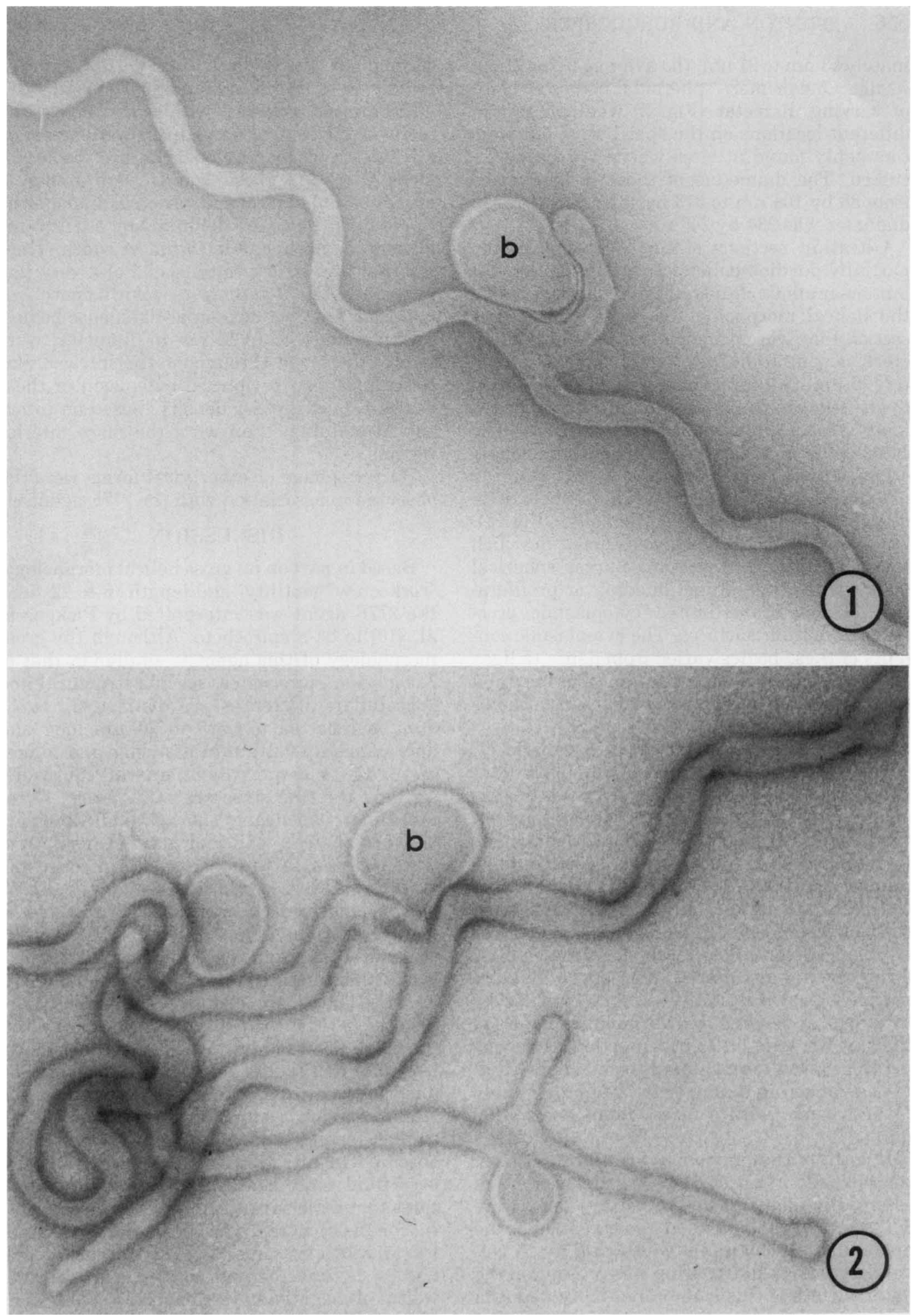

Frg. 1. Negative (PTA)-stained $277 F$ specimen from coxal fluid of $O$. moubata tick. Note helical morphology, spheroidal body (b) and short branched arm. Magnification, $\times 66,000$.

FIG. 2. Helical 277F specimens exhibiting spheroidal bodies (b) located at sites of branching (PTA stained). Magnification, $\times 60,000$. 
mately $53 \mathrm{~nm}$ to $91 \mathrm{~nm}$, the average being about $70 \mathrm{~nm}$. One or more spheroidal bodies or blebs of varying diameter (Fig. 2) were present in different locations on the spiral arms but were commonly found at sites where branching occurred. The diameters of these bodies varied from 88 by $108 \mathrm{~nm}$ to 373 by $433 \mathrm{~nm}$; the mean diameter was 234 by $246 \mathrm{~nm}$.

Ultrathin sections of the $277 \mathrm{~F}$ agent from partially purified pellets of chicken embryo allantoic-amniotic fluids (Fig. 3) also revealed the helical morphology of the cells. In cross section they were principally ovoid, with diameters varying from 79 to $109 \mathrm{~nm}$ (mean diameter, $96 \mathrm{~nm}$ ). All forms observed were delimited by a trilayered plasma membrane approximately 8 to $9 \mathrm{~nm}$ in diameter (Fig. 4). The cytoplasmic matrix varied in composition and organization from dense to light staining patches of amorphous material to an anastomosing meshwork of fine filaments (Fig. 4). Occasionally, small blebs were noted in which fine filaments were present. Larger spherical bodies (Fig. 5) exhibited budding or proliferation of membrane-limited cytoplasmic processes from their surfaces. The cytoplasmic contents of these bodies varied from dense to light staining and appeared to contain ribosomes and membrane-limited spherical bodies or vacuoles (Fig. 5).

Growth of the $277 \mathrm{~F}$ agent in organs of $O$. moubata ticks was typically heavy in the central ganglion and coxal organs, whereas moderate growth was manifest in the Malpighian tubules. The organisms were localized primarily in extracellular spaces underlying the outer connective tissue sheath (neural lamella or basement membrane) and in close association with subjacent cells (Fig. $\hat{6}$ ). Their in situ gross morphology continued to be of general helical form, yet they also displayed greater individual morphological variability. This was manifest by irregular bending and variable diameters to their width (Fig. 6). In cross section, they varied from ovoid to irregularly ovoid shape (Fig. 7) and ranged in diameter from approximately 74 to $300 \mathrm{~nm}$, with a mean diameter of $>100$ $\mathrm{nm}$.

In each of the previously mentioned organs, the helical portion of these organisms were of essentially identical fine structure. They were delimited by a trilayered plasma membrane approximately $9.0 \mathrm{~nm}$ in width (Fig. 7). A velvety glycocalyx-like coating was present on the outer surface of this membrane. The cytoplasm was organized basically as a reticulum of fine filamentous strands (Fig. 8) containing patches of stainable amorphous material. Ribosomallike particles were irregularly dispersed throughout the helices and varied approximately 14 to $19 \mathrm{~nm}$ in diameter.

Organisms growing within the neural lamella of the central nerve mass were occasionally observed to develop spherical bodies or blebs (Fig. 9). These bodies were round to broadly ovoid in form and varied in diameter up to $740 \mathrm{~nm}$. They were delimited by a trilayered plasma membrane, 9 to $10 \mathrm{~nm}$ in width. Their internal fine structure consisted of a very fine reticulum (Fig. 9) interspersed with amorphous material. Distinct ribosomal-like dense bodies, approximately 12 to $13 \mathrm{~nm}$ in diameter, were lightly dispersed throughout the intracellular reticulum. The peripheral cytoplasm of these bodies was of greater density, based on intensity of staining, than were the more interior regions.

Bacteriophage or other viral forms were not observed in association with the $277 \mathrm{~F}$ agent.

\section{DISCUSSION}

Based in part on its gross helical morphology, "corkscrew" motility, and length (6 to $12 \mu \mathrm{m}$ ), the $277 \mathrm{~F}$ agent was interpreted by Pickens et al. (10) to be a spirochete. Although the gross morphology of this agent is similar to that of Treponema spirochetes, specific structural and subcellular differences are distinct. $T$. palli$d u m$ is reported to be 5 to $20 \mu \mathrm{m}$ long and approximately $0.2 \mu \mathrm{m}$ in diameter and to possess a 15- to 20-nm trilaminar wall (5). In describing the fine structure of $T$. reiter, Ryter and Pillot (13) clearly showed axial filaments between the cell wall and plasma membrane, which gave rise to both the spiral form and motility of these organisms. Cells of the $277 \mathrm{~F}$ agent conformed closely in length to those of members of the genus Treponema; however, the width, with some exceptions in tick tissues, was usually half ( $100 \mathrm{~nm}$ or less) the diameter of treponemal spirochetes. The diameters of negatively stained $277 \mathrm{~F}$ specimens from coxal fluids of $O$. moubata ticks were consistently less than half that of $T$. pallidum; this may be due, in part, to shrinkage during negative staining and subsequent drying. A consistently smaller mean diameter of the $277 \mathrm{~F}$ agent, when observed in ultrathin sections of chicken embryo fluid concentrates and tick tissues, indicates that little shrinkage of negatively stained specimens occurred. The considerable variability in width of some $277 \mathrm{~F}$ specimens in tick tissues is unaccounted for. In general, the width of negatively stained $277 \mathrm{~F}$ specimens conformed closely with measurements reported for negatively stained specimens of Spiroplasma citri and with specimens of $S$. citri fixed with glutaraldehyde-sorbitol complete medium 

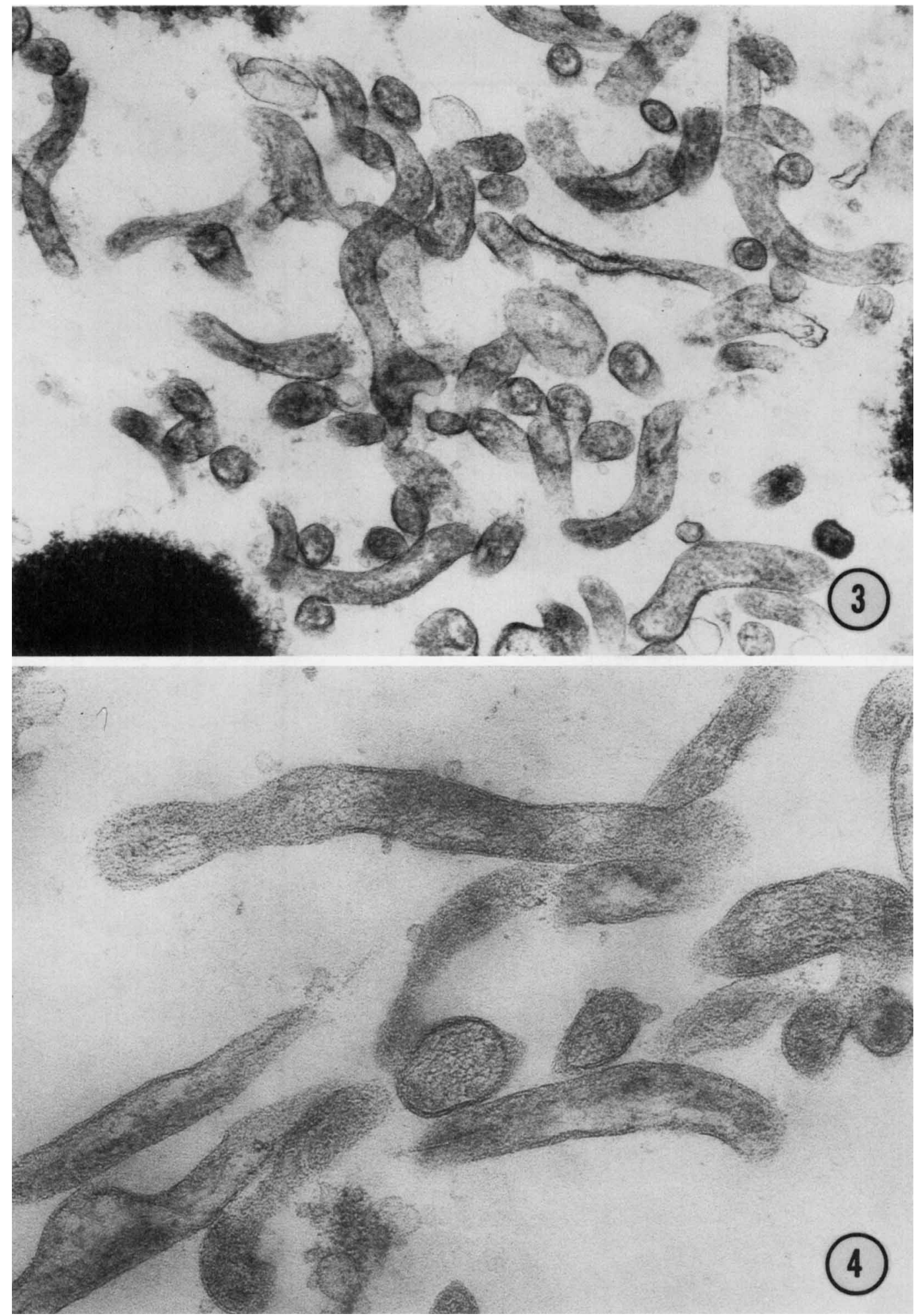

Fig. 3. Ultrathin section of $277 F$ specimens from partially purified amniotic-allantoic chicken embryo fluids. Magnification, $\times 63,000$.

Fig. 4. Fine structure of $277 \mathrm{~F}$ organisms from chicken embryo fluids reveals a limiting plasma membrane and cytoplasm containing anastomosing fibrils and amorphous material. Magnification, $\times 105,000$. 

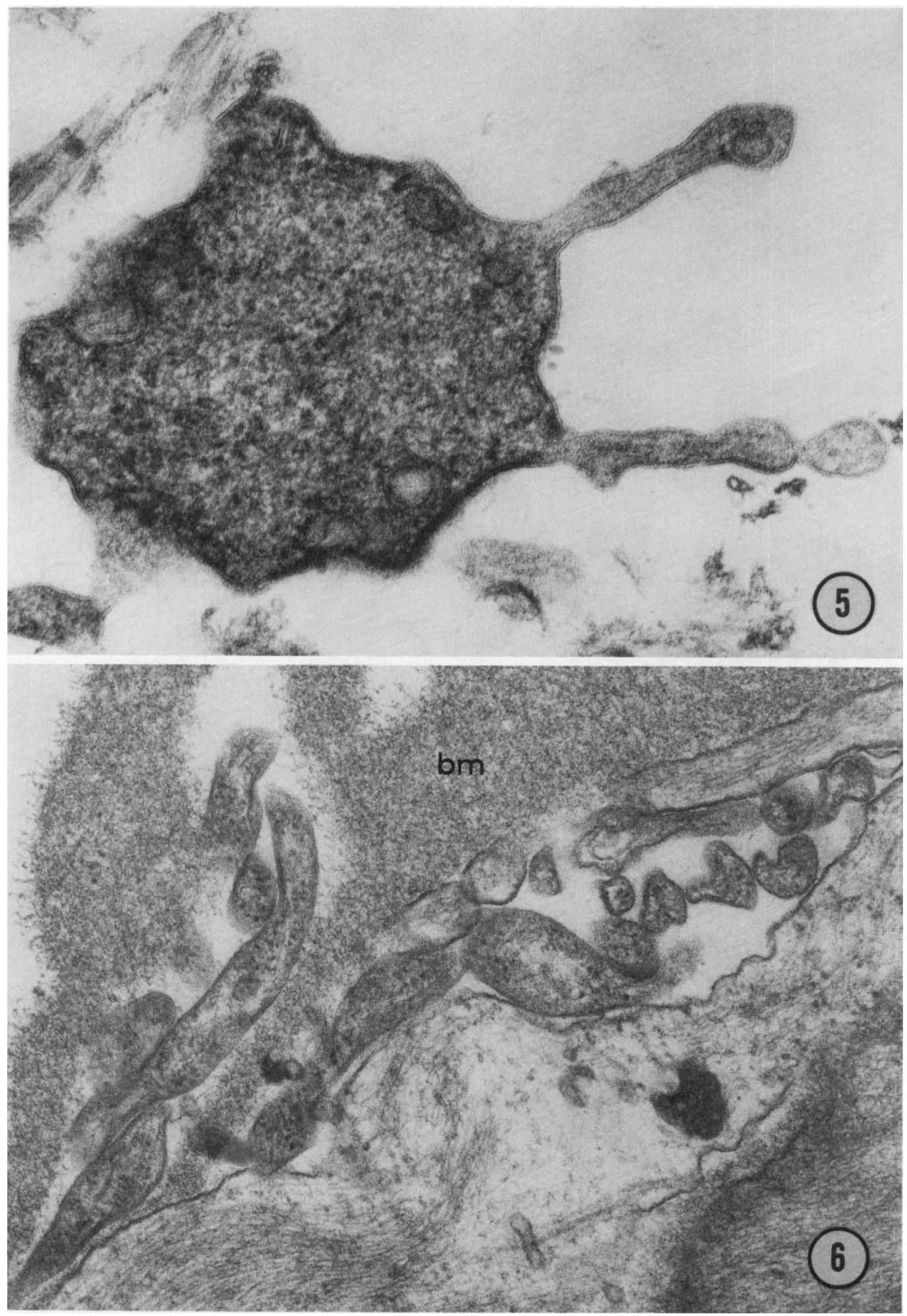

FIG. 5. Ultrathin section through a spheroidal body with proliferating membrane limited cytoplasmic processes. Magnification, $\times 92,000$.

FIG. 6. Fine structure of $277 \mathrm{~F}$ specimens in extracellular space between basement membrane (bm) and underlying cells of coxal organ of $O$. moubata. Note ribosomes and fibrillar reticulum in cytoplasmic ground substance of these organisms. Magnification, $\times 59,000$. 


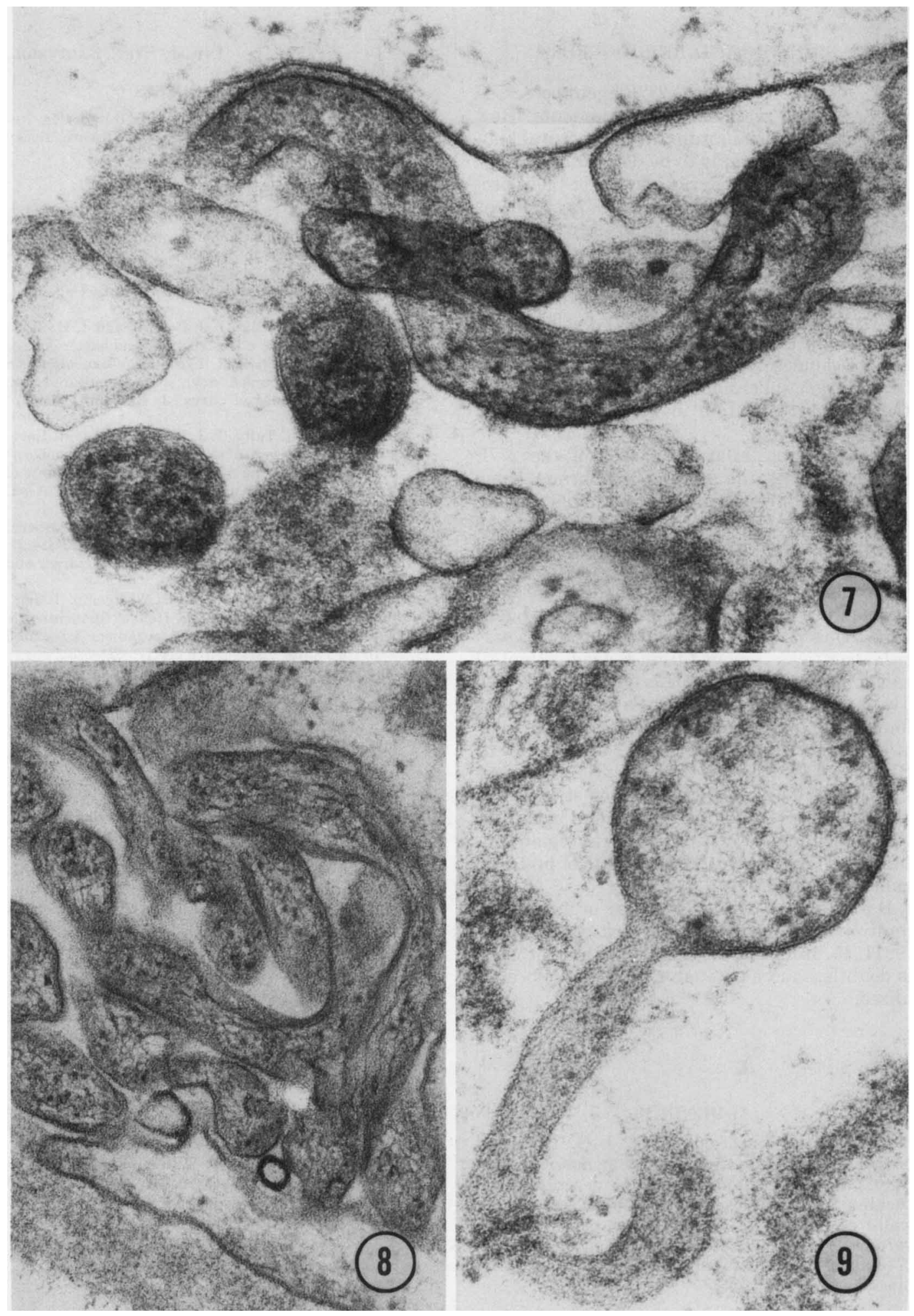

FIG. 7. Cross and longitudinal sections of $277 \mathrm{~F}$ specimens in neural sheath of central nerve mass of $O$. moubata. Organisms are delimited by a trilayered unit membrane with a velvety glycocalyx-like coat on exterior surface and contain ribosomes throughout their cytoplasm. Magnification, $\times 111,000$.

Fig. 8. Prominent fibrillar reticulum and ribosomes in cytoplasm of $277 \mathrm{~F}$ organisms located in extracellular space subjacent to basement membrane of coxal organ of O. moubata. Magnification, $\times 81,000$.

FIG. 9. Spherical body of $277 F$ organism possessing a distinctly trilaminar unit membrane with a velvety coat on its exterior surface. The cytoplasm consists of a fine reticulum with patches of amorphous material and ribosomes. Ribosomes are also present in helical portion of organism. Magnification, $\times 111,000$. 
$(3,4)$. As with $S$. citri, the $277 \mathrm{~F}$ agent possessed neither a cell wall nor axial filaments. How these organisms maintain their structural helical symmetry remains to be determined.

The presence of spherical bodies or blebs protruding from the surface of the $277 \mathrm{~F}$ agent as extensions of the plasma membrane constituted another important similarity in the gross morphology of this organism with $S$. citri $(3,4)$. Pickens et al. (10) suggested that granules associated with the $277 \mathrm{~F}$ agent may be infectious and capable of producing spirochetes. The presence of slender cytoplasmic processes radiating from large spheroidal bodies suggests that these spheres function in the budding of new helices.

Several subcellular structures of the $277 \mathrm{~F}$ agent, such as the plasma membrane, ribosomes, fibrillar reticulum of probable genetic material, and a thin glycocalyx-like coat on the cell surface, agreed closely in morphology and size with the same structures of $S$. citri $(3,4)$.

Similarity is also evident between the $277 \mathrm{~F}$ agent and the suckling mouse cataract agent (SMCA) isolated from a pool of four $H$. leporispalustris ticks removed from a dead cottontail rabbit (Sylvilagus putorius) in Georgia (2). This agent, first thought to be a virus, was later found to be a member of the order Mycoplasmatales $(17 ;$ R. F. Zeigel and H. F. Clark, J. Cell. Biol. 43:1632). Like the 277F agent, SMCA does not possess a cell wall, and its fine structure is characterized by a dense-staining, granular, cortical cytoplasm, with the central region containing a fine ribbon-like reticulum of probable genomic material.

Based on the ability of these organisms to multiply prolifically in both ticks and insects $(9,11,15,16)$, their association with arthropods is doubtless more extensive than heretofore realized.

\section{ADDENDUM}

Upon completion of our study, J. G. Tully and associates called our attention to a manuscript (submitted for publication to Nature) describing the suckling mouse cataract agent (SMCA) as a helical, wall-free prokaryote (Spiroplasma) pathogenic for vertebrates. These authors also suggest that the $277 \mathrm{~F}$ agent may be similar to SMCA and other spiroplasmas.

\section{REPRINT REQUESTS}

Address reprint requests to: Dr. Willy Burgdorfer, National Institute of Allergy and Infectious Disease, Rocky Mountain Laboratory, Hamilton, Mont. 59840.

\section{LITERATURE CITED}

1. Chen, T., and R. R. Granados. 1970. Plant-pathogenic mycoplasma-like organisms: maintenance in vitro and transmission to Zea mays L. Science 167:16331636.

2. Clark, H. F. 1964. Suckling mouse cataract agent. J. Infect. Dis. 114:476-487.

3. Cole, R. M., J. G. Tully, T. J. Popkin, and J. M. Bové 1973. Morphology, ultrastructure, and bacteriophage infection of the helical mycoplasma-like organism (Spiroplasma citri gen. nov., sp. nov.) cultured from "stubborn" disease of citrus. J. Bacteriol. 115:367386.

4. Cole, R. M., J. G. Tully, T. J. Popkin, and J. M. Bové. 1973. Ultrastructure of the agent of citrus "stubborn" disease. Mycoplasma and mycoplasma-like agents of human, animal, and plant diseases. Ann. N. Y. Acad. Sci. 225:471-493.

5. Davis, B. D., R. Dulbecco, H. N. Eisen, H. S. Ginsberg, and W. B. Wood, Jr. 1973. Spirochetes, p. 883-884. In B. D. Davis et al., Microbiology, 2nd ed. Harper and Row, Hagerstown, Md.

6. Davis, R. E., J. F. Worley, R. F. Whitcomb, T. Ishijima, and R. L. Steere. 1972. Helical filaments produced by a mycoplasma-like organism associated with corn stunt disease. Science 176:521-523.

7. Granados, R. 1969. Electron microscopy of plants and insect vectors infected with the corn stunt disease agent. Contrib. Boyce Thompson Inst. 24:173-188.

8. Luft, J. H. 1961. Improvements in epoxy embedding methods. J. Biophys. Biochem. Cytol. 9:409-414.

9. Oishi, K., and D. F. Poulson. 1970. A virus associated with SR-Spirochetes of Drosophila nebulosa. Proc. Natl. Acad. Sci. U.S.A. 67:1565-1572.

10. Pickens, E. G., R. K. Gerloff, and W. Burgdorfer. 1968. Spirochete from the rabbit tick, Haemaphysalis leporispalustris (Packard). J. Bacteriol. 95:291-299.

11. Poulson, D. F., and B. Sakaguchi. 1961. Nature of "sexratio" agent in Drosophila. Science 133:1489-1490.

12. Reynolds, E. S. 1963. The use of lead citrate at high $\mathrm{pH}$ as an electron opaque stain in electron microscopy. $J$. Cell. Biol. 17:208-212.

13. Ryter, A., and J. Pillot. 1963. Etude au microscope electronique de la structure externe et interne du Treponeme reiter. Ann. Inst. Pasteur 104:496-501.

14. Saglio, P., M. Lhospital, D. Laflèche, G. DuPont, J. M. Bové, J. G. Tully, and E. A. Freundt. 1973. Spiroplasma citri gen. and sp. n.: a mycoplasma-like organism associated with "stubborn" disease of citrus. Int. J. Syst. Bacteriol. 23:191-204.

15. Whitcomb, R. F., and J. G. Tully. 1973. Spiroplasmas and acholeplasmas: multiplication in insects. Science 183:1251-1253.

16. Whitcomb, R. F., and D. L. Williamson. 1975. Helical wall-free prokaryotes in insects: multiplication and pathogenicity. Pathobiology of invertebrate vectors of disease. Ann. N. Y. Acad. Sci. 266:260-275.

17. Zeigel, R. F., and H. F. Clark. 1974. Electron microscopy of the suckling mouse cataract agent: a noncultivable animal pathogen possibly related to mycoplasma. Infect. Immun. 9:430-443. 